\title{
Risk factors and long-term outcomes of acute kidney injury complication after type A acute aortic dissection surgery in young patients
}

Qiuyan Zong, Min Ge, Tao Chen, Cheng Chen, Zhigang Wang and Dongjin Wang*

\begin{abstract}
Objective: To identify risk factors and long-term outcomes of acute kidney injury (AKI) in young patients who underwent type A acute aortic dissection (TA-AAD) emergency surgeries.

Methods: This retrospective study enrolled 121 consecutive patients less than 40 years old who received TA-AAD emergency surgeries between January 2014 to December 2018 in Nanjing Drum Tower hospital. The diagnosis of AKI was made based on the KDIGO criteria. Multivariable regression analysis was performed to identify risk factors for postoperative AKI. Kaplan-Meier curves were generated to compare long-term outcomes between patients with and without AKI complication after TA-AAD surgeries.

Results: Among all enrolled patients, AKI occurred in 51 patients (42.1\%) and renal replacement therapy (RRT) was required in 15 patients (12.4\%). The development of postoperative AKI was associated with increased 30-day mortality $(P=0.041)$, longer ICU stay time $(P<0.001)$ and hospital stay time $(P=0.006)$. Multivariable analysis indicated that elevated preoperative serum cystatin $C(s C y C)(O R=6.506,95 \%$ Cl: $1.852-22.855, P=0.003)$ was the only independent risk factor for developing AKI. The areas under the receiver-operating characteristic curve (AUC) of preoperative sCyC was 0.800 (95\% Cl: 0.719, 0.882). Preoperative sCyC had a sensitivity of $64.7 \%$ and a specificity of $83.8 \%$ in diagnosing postoperative AKI with a cut-off value of $0.895 \mathrm{mg} / \mathrm{L}$. In addition, our data suggested there was no difference discovered regarding long-term cumulative survival rate between patients with and without AKI during a median 29 months follow-up period.
\end{abstract}

Conclusions: Postoperative AKI after TA-AAD surgeries was relatively common in young patients and associated with increased short-term mortality. Elevated preoperative sCyC was identified as an independent risk factor for AKI with potential diagnostic merit.

Keywords: Acute kidney injury, Type A aortic dissection, Risk factors, Young age, Cystatin C

\footnotetext{
* Correspondence: glyywdi@163.com

Department of Cardio-Thoracic Surgery, Nanjing Drum Tower Hospital, The Affiliated Hospital of Nanjing University Medical School, Nanjing 210008, China
}

(c) The Author(s). 2020 Open Access This article is licensed under a Creative Commons Attribution 4.0 International License, which permits use, sharing, adaptation, distribution and reproduction in any medium or format, as long as you give appropriate credit to the original author(s) and the source, provide a link to the Creative Commons licence, and indicate if changes were made. The images or other third party material in this article are included in the article's Creative Commons licence, unless indicated otherwise in a credit line to the material. If material is not included in the article's Creative Commons licence and your intended use is not permitted by statutory regulation or exceeds the permitted use, you will need to obtain permission directly from the copyright holder. To view a copy of this licence, visit http://creativecommons.org/licenses/by/4.0/. The Creative Commons Public Domain Dedication waiver (http://creativecommons.org/publicdomain/zero/1.0/) applies to the data made available in this article, unless otherwise stated in a credit line to the data. 


\section{Introduction}

Aortic dissection (AD) is a life-threatening disease. Despite recent advances in clinical management and surgical techniques, type $\mathrm{A}$ acute aortic dissection (TA-AAD) still carries a high burden of morbidity and mortality [1]. Acute kidney injury (AKI) is a relative common serious complication after TA-AAD repair surgery. It had been proved as an independent risk factor for disease prognosis in patients received TA-AAD surgeries [2]. Early identification of AKI in postoperative period allow timely therapeutic intervention to prevent disease progression and improve prognosis [3].

$\mathrm{AD}$ is relatively uncommon in young patients and it has been suggested only $6.4 \%$ of all thoracic aortic dissections occurred in patients under 40 years old [4]. Some reports have been published characterizing young patients with aortic dissection [4-6]. However, the incidence and long-term outcome of AKI in young patients who received extended aortic repairments have been not well studied. The primary aims of this study were to identify the incidence and risk factors of AKI in young patients who received surgical treatment for TA-AAD and to investigate its impact on both short- and longterm outcomes.

\section{Methods}

The ethics committee of Nanjing Drum Tower hospital approved this retrospective study and waived the need for individual informed consent due to the retrospective nature of this study.

\section{Patients}

The medical records of patients (age $<40$ ) who received emergency TA-AAD surgery between January 2014 and December 2018 were reviewed retrospectively. Patients with history of preoperative renal replacement therapy (RRT) and died within $24 \mathrm{~h}$ postoperatively were excluded. After screening, a total of 121 consecutive patients were enrolled for the present study.

\section{Diagnostic criteria for postoperative AKI}

The postoperative AKI was diagnosed according to the Kidney Disease Improving Global Outcomes (KDIGO) criteria [7]. The AKI criteria comprised of an absolute increase in serum creatinine $(\mathrm{sCr})$ of more than or equal to $0.3 \mathrm{mg} / \mathrm{dL}$ or a percentage increase in the $\mathrm{sCr}$ of more than or equal to $50 \%$ up to 7 days after surgery.

\section{Surgical procedures}

TA-AAD surgeries were performed following standard procedures. Specifically, after systemic heparinization, cardiopulmonary bypass (CPB) was established by cannulation of femoral artery or right axillary artery and atrium. When patients were cooled to $18{ }^{\circ} \mathrm{C}-20{ }^{\circ} \mathrm{C}$ (nasopharyngeal temperature), the circulation was stopped, and the flow rate was reduced to $3-5 \mathrm{ml} / \mathrm{kg} /$ min. Bentall procedure or ascending aorta replacement was performed depending on conditions of aortic regurgitation. After the completion of distal and transverse anastomoses, systemic rewarming was started and the proximal reconstruction marked the completion of a standard CPB surgery.

\section{Statistical analysis}

Data were analyzed with SPSS software (version 25.0 IBM Corp, Armonk, NY). Continuous variables were expressed as median and interquartile (IQR), the student $t$-test was applied for normally distributed continuous variables and Mann-Whitney $U$ test for nonnormally distributed variables. Categorical variables were expressed as number and percentage of patients and analyzed with Chi-square or Fisher exact test, as appropriate. Logistic regression models were used to identify multivariable predictors for AKI. Considering the relatively low number of AKI patients $(n=51)$ in the cohort and in order to avoid overfitting in the model, the significant variables identified by univariable analysis were further evaluated in multivariable analysis. Receiveroperating characteristic (ROC) curves were constructed to assess the diagnostic potential of preoperative serum cystatin $\mathrm{C}(\mathrm{sCyC})$. The optimal cutoff was assessed by You-den's index. Linear regression analysis was used to assess the correlation between the preoperative sCyC and $\mathrm{sCr}$. Crude survival rate was estimated with KaplanMeier method. Differences in survival rate between groups were analyzed with log-rank tests. A $p$ value of less than 0.05 was considered statistically significant.

\section{Results}

\section{Demographic and clinical features}

During screening period, 125 patients received emergency operation for TA-AAD. Among these patients, 1 required hemodialysis and 3 died within $24 \mathrm{~h}$ after operation were excluded from the study. As a result, 121 patients were enrolled in the study and 51 (42.1\%) developed AKI.

Patient demographic and surgical features were summarized in Table 1 and Table 2. The median age of all enrolled patients was 34 years (IQR 30 to 36 years). Compared to patients who did not develop AKI, the prevalence of hypertension history and preoperative sCyC level was significantly higher in patients with AKI. In terms of surgical operative parameters, patients with AKI required less frequent intra-operative aortic valve management, while the proportion of total arch replacement (TAR) and the duration of deep hypothermic circulatory arrest (DHCA) were significantly increased in patients with AKI compared to patients without AKI. 
Table 1 Comparison of preoperative variables

\begin{tabular}{|c|c|c|c|c|}
\hline Variables & Total $(n=121)$ & AKI $(n=51)$ & Non-AKI $(n=70)$ & $P$ Value $^{\mathrm{a}}$ \\
\hline \multicolumn{5}{|l|}{ Demographic data } \\
\hline Age (year) & $34.0(30.0,36.0)$ & $35.0(31.0,37.0)$ & $33.0(30.0,38.0)$ & 0.204 \\
\hline Male (\%) & $99(81.8)$ & $40(78.4)$ & $59(84.3)$ & 0.410 \\
\hline BMI (kg/m2) & $25.7(22.0,30.6)$ & $26.3(23.9,32.1)$ & $24.7(20.1,32.8)$ & 0.091 \\
\hline \multicolumn{5}{|l|}{ Medical history } \\
\hline Hypertension (\%) & $60(49.6)$ & $36(70.6)$ & $25(35.7)$ & $<0.001$ \\
\hline Diabetes mellitus (\%) & $1(0.8)$ & $1(2.0)$ & $0(0)$ & 0.421 \\
\hline Previous cardiac surgery (\%) & $6(5.0)$ & $3(5.9)$ & $3(4.3)$ & 0.696 \\
\hline Previous Coronary artery disease (\%) & $3(2.5)$ & $3(5.9)$ & $0(0)$ & 0.072 \\
\hline Cerebrovascular disease (\%) & $1(0.8)$ & $1(2.0)$ & $0(0)$ & 0.421 \\
\hline LVEF (\%) & $60.0(56.0,60.0)$ & $58.5(54.8,60.0)$ & $60.0(57.0,60.5)$ & 0.257 \\
\hline Pericardial effusion (\%) & $1(0.8)$ & $0(0)$ & $1(1.4)$ & 1.000 \\
\hline \multicolumn{5}{|l|}{ Preoperative laboratory data } \\
\hline WBC (109/L) & $11.9(9.1,14.9)$ & $12.2(9.0,15.9)$ & $11.3(9.2,14.2)$ & 0.171 \\
\hline $\mathrm{sCr}(\mu \mathrm{mol} / \mathrm{L})$ & $71.8(56.7,99.7)$ & $80.0(58.9,103.0)$ & $68.0(53.9,97.0)$ & 0.099 \\
\hline $\mathrm{sCyC}$ & $0.78(0.55,1.22)$ & $1.21(0.76,1.67)$ & $0.63(0.49,0.84)$ & $<0.001$ \\
\hline PLT (109/L) & $155.5(108.8,203.0)$ & $165.0(108.0,208.0)$ & $153.0(109.5,198.0)$ & 0.669 \\
\hline ALB (g/L) & $38.6(35.1,41.6)$ & $38.0(32.9,41.2)$ & $39.5(35.4,42.4)$ & 0.120 \\
\hline Fibrinogen (g/L) & $2.5(2.0,3.5)$ & $2.4(2.0,3.5)$ & $2.6(1.8,3.4)$ & 0.998 \\
\hline Triglyceride (mmol/L) & $1.2(0.8,1.7)$ & $1.3(0.9,2.9)$ & $1.2(0.7,1.5)$ & 0.090 \\
\hline D-dimer (ng/mL) & $3.1(1.7,5.2)$ & $3.7(2.2,5.3)$ & $2.9(1.5,5.1)$ & 0.215 \\
\hline
\end{tabular}

Data presented as $\mathrm{n}(\%)$; median (IQR)

Abbreviations: BMI body mass index, LVEF left ventricular ejection fraction, WBC white blood cell, $S C r$ serum creatinine, $S C y C$ serum cystatin $C, P L T$ platelet, $A L B$ albumin

${ }^{\text {a }} P$ values indicate differences between $\mathrm{AKI}$ and Non-AKI. $P<0.05$ was considered statistically significant

In-hospital outcomes were shown in Table 3. Postoperative mechanical ventilation duration, intensive care unit (ICU) and hospital stay were all prolonged in patients with AKI compared to patients without AKI. Unsurprisingly, postoperative hemodialysis and 30-day mortality were also increased in patients with AKI.

Next, we examined variables mentioned above in the methods section by multivariable logistic regression assay and discovered that elevated preoperative $\mathrm{sCyC}$ (OR, 1.029; 95\% CI, 1.007-1.051; $P=0.009$ ) was identified as an independent risk factor associated with postoperative AKI (Table 4).

In addition, as presented in Fig. 1, we conducted ROC curve assay and calculated the areas under the ROC curve (AUC) of preoperative $\mathrm{sCyC}$ and $\mathrm{sCr}$. The AUC of preoperative $\mathrm{sCyC}$ and $\mathrm{sCr}$ was 0.800 (95\% CI: 0.719, 0.882; $P<0.001$ ) and 0.589 (95\% CI: 0.485, 0.692; $P=$ 0.099 ) respectively, and the AUC of preoperative sCyC showed a higher value to predict postoperative AKI $(P<$ 0.001). Our examination suggested that preoperative

Table 2 Comparison of operative variables

\begin{tabular}{lllll}
\hline Variables & Total $(\boldsymbol{n}=\mathbf{1 2 1})$ & AKI $(\boldsymbol{n}=\mathbf{5 1})$ & Non-AKI $(\boldsymbol{n}=\mathbf{7 0})$ & $\boldsymbol{P}$ Value \\
\hline TAR (\%) & $75(62.0)$ & $40(78.4)$ & $35(50.0)$ & $\mathbf{0 . 0 0 1}$ \\
CABG/MVR/MVP/TVP (\%) & $11(9.1)$ & $5(9.8)$ & $6(8.6)$ & 1.000 \\
Aortic valve (\%) & $57(47.1)$ & $13(25.5)$ & $44(62.9)$ & $<\mathbf{0 . 0 0 1}$ \\
CPB time (min) & $235.0(203.0,273.5)$ & $239.5(213.5,306.0)$ & $231.0(197.3,269.0)$ & 0.075 \\
Aortic cross-Clamp time (min) & $173.5(138.0,209.5)$ & $175.0(136.8,222.3)$ & $170.5(138.0,202.5)$ & 0.558 \\
DHCA time (min) & $30.0(19.5,38.0)$ & $33.0(27.8,40.3)$ & $25.0(16.0,35.0)$ & $\mathbf{0 . 0 0 1}$ \\
\hline
\end{tabular}

Data presented as $\mathrm{n}(\%)$; median (IQR)

Abbreviations: TAR total arch replacement, CABG coronary artery bypass graft, MVR mitral valve replacement, MVP mitral valvuloplasty, TVP tricuspid valvuloplasty, $C P B$ cardiopulmonary bypass, $D H C A$ deep hypothermic circulatory arrest

${ }^{\mathrm{a}} P$ values indicate differences between AKI and Non-AKI. $P<0.05$ was considered statistically significant 
Table 3 Comparison of postoperative variables

\begin{tabular}{|c|c|c|c|c|}
\hline Variables & Total $(n=121)$ & AKI $(n=51)$ & Non-AKI $(n=70)$ & $P$ Value $^{\mathrm{a}}$ \\
\hline Drainage volume $24 \mathrm{~h}$ after surgery $(\mathrm{ml})$ & $540.0(300.0,907.5)$ & $650.0(292.5,1256.3)$ & $515.0(307.5,852.5)$ & 0.288 \\
\hline Re-exploration for bleeding (\%) & $3(2.5)$ & $1(2.0)$ & $2(2.9)$ & 1.000 \\
\hline Dialysis (\%) & $15(12.4)$ & $15(29.4)$ & $0(0)$ & $<0.001$ \\
\hline Ventilation time (hour) & $16.0(12.0,36.0)$ & $29.5(16.0,64.0)$ & $14.1(9.9,19.0)$ & $<0.001$ \\
\hline Stroke (\%) & $12(9.9)$ & $3(5.9)$ & $9(12.9)$ & 0.205 \\
\hline Paraplegia (\%) & $3(2.5)$ & $0(0)$ & $3(4.3)$ & 0.262 \\
\hline Tracheostomy (\%) & $9(7.4)$ & $3(5.9)$ & $6(8.6)$ & 0.732 \\
\hline Deep sternal wound infection (\%) & $1(0.8)$ & $0(0)$ & $1(1.4)$ & 1.000 \\
\hline 30-day mortality (\%) & $7(5.8)$ & $6(11.8)$ & $1(1.4)$ & 0.041 \\
\hline ICU Stay time (day) & $4.0(3.0,7.0)$ & $6.0(4.0,10.0)$ & $3.5(3.0,5.0)$ & $<0.001$ \\
\hline Hospital stay time (day) & $20.0(16.0,26.5)$ & $24.0(17.0,33.0)$ & $19.0(15.0,25.0)$ & 0.006 \\
\hline
\end{tabular}

Data presented as $\mathrm{n}(\%)$; median (IQR)

Abbreviations: ICU intensive care unit

${ }^{\mathrm{a}} P$ values indicate differences between AKI and Non-AKI. $P<0.05$ was considered statistically significant

sCyC had a sensitivity of $64.7 \%$ and a specificity of $83.8 \%$ in predicting AKI with a diagnostic cut-off value of $0.895 \mathrm{mg} / \mathrm{L}$.

Unfortunately, 7 patients died during hospitalization. Among the remaining 114 patients, 5 patients that lost to follow-up and 1 patient who committed suicide 6 months after hospital discharge were excluded from the following survival analysis. The median follow-up period was 29 months. 5 patients in the AKI group and 3 patients in the non-AKI group died during follow-up period. There was no significant difference identified by Kaplan-Meier survival curves between two groups regarding long-term survival (Fig. 2; $p=0.412$ by log-rank test).

\section{Discussion}

To our knowledge, this was the first study to examine the incidence, risk factors and outcomes for AKI complication after TA-AAD emergency surgery in young patients. This study shows that postoperative AKI was associated with increased 30-day mortality rate in young patients who received emergency TAAAD surgery. Multivariable logistic regression analysis and ROC curve assay demonstrated that elevated preoperative $\mathrm{sCyC}$ was an independent risk factor and might be considered as an diagnostic marker for postoperative AKI.

The incidence of postoperative AKI in our study was $42.1 \%$ and consistent to previous studies $[1,2]$, which suggested that postoperative AKI was a relative common complication in young patients. Similar to previous studies, 15 patients $(12.4 \%)$ in this cohort required postoperative RRT, and all of whom belong to AKI group [8-10]. A previous meta-analysis suggested that patients with AKI had higher risk of experiencing chronic kidney disease and end-stage renal disease [11]. Despite significant advance in intensive care and renal replacement techniques have been achieved in recent years, the shortand long- term mortality of patients with AKI remains relatively high [12]. Our data suggested that young age was not a protective factor for postoperative AKI and cautions should be applied in preventing postoperative AKI in young patients.

The 30-day mortality of all enrolled patients was 5.8\% (7 out of 121 patients), which was lower than previous studies which enrolled older patients $[9,13]$, indicating age as a significant risk factor affect 30-day mortality [14-16]. However, our data suggested a significant

Table 4 Multivariable analysis of risk factors for acute kidney injury with KDIGO

\begin{tabular}{llll}
\hline Variable & OR & $\mathbf{9 5 \%} \mathbf{C l}$ & $\boldsymbol{P}$ Value \\
\hline Hypertension & 0.857 & $0.231-3.178$ & 0.818 \\
SCyC & 6.506 & $1.852-22.855$ & $\mathbf{0 . 0 0 3}$ \\
Aortic valve & 0.310 & $0.078-1.226$ & 0.095 \\
TAR & 1.465 & $0.352-6.093$ & 0.599 \\
DHCA time & 1.024 & $0.973-1.078$ & 0.818 \\
Ventilation time & 1.001 & $0.993-1.010$ & 0.762 \\
\hline
\end{tabular}

Abbreviations: SCyC serum cystatin C, TAR total arch replacement, DHCA deep hypothermic circulatory arrest, $O R$ odds ratio, $\mathrm{Cl}$ confidence interval $P<0.05$ was considered statistically significant 


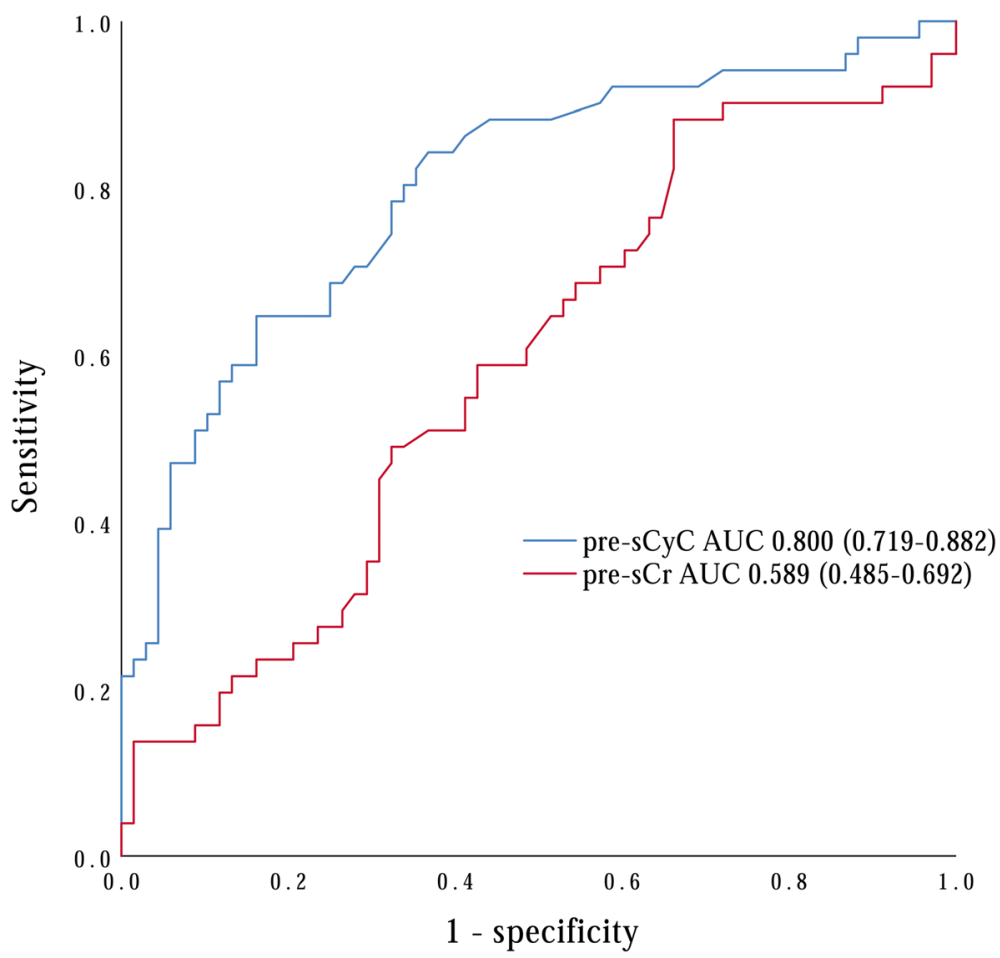

Fig. 1 Receiver-operating characteristics of serum cystatin $C$ and serum creatinine before the operation (AUC, areas under receiver-operating characteristic curve; pre-sCyC, preoperative serum cystatin C; pre-sCr, preoperative serum creatinine)

difference of 30-day mortality between patients with and without AKI. It was in consistent with previous studies suggesting postoperative AKI strongly influenced patients outcomes [1,9,17]. While regarding long-term mortality rate, we only observed a numerical difference but did not reach statistical significance between patients with and without postoperative AKI. This might due to the relatively small number of patients and insufficient follow-up time.

Logistic regression model suggested elevated preoperative $\mathrm{sCyC}$ as an independent risk factor for postoperative AKI. This discovery was consistent with previous study demonstrating elevated $\mathrm{sCyC}$ was an important trigger for AKI in patients underwent cardiac surgeries [18, 19]. While for TA-AAD surgical repair, there were few studies applied $\mathrm{sCyC}$ to elvaluate renal function. Another main finding of our study was the ability of preoperative $\mathrm{sCyC}$ in predicting persistent AKI with a high level of sensitivity (64.7\%) and specificity (83.3\%). The predictive ability was comparable to that reported by Parikh et al. [20] and Wang et al. [19], but much higher than one of our previous studies which enrolled both young and old patients [21]. This implied that $\mathrm{sCyC}$ had a better predictive ability in young patients. Some studies had shown that serum $\mathrm{sCyC}$ was a better indicator of kidney function compared to $\mathrm{sCr}[22,23]$, and increased
24-48 h earlier than conventional clinical diagnosis of AKI could be made [24, 25]. As a well-accepted marker of renal function, $\mathrm{sCr}$ has several limitations and can be affected by postoperative hemodilution, muscle wasting, and malnutrition [26] which sometimes might result in overestimation of the kidney function. As $\mathrm{sCyC}$ does not secrete from tubular and excrete in urine solely through filtration, it has the potential to be a useful alternative marker for detecting both chronic and acute changes in glomerular filtration rate [27]. Our studies demonstrated that preoperative $\mathrm{sCyC}$ was an independent risk factor for postoperative AKI. And our data suggested that monitoring preoperative $\mathrm{sCyC}$ level might be helpful to identify patients who have increased risk of developing renal malfunction.

\section{Study limitations}

This study has some limitations. Firstly, the relatively small number of patients enrolled in this study might have insufficient power to identify potential confounding baseline characteristics. Secondly, we only used sCr level for KDIGO classification which might have resulted in an underestimation of the incidence of AKI. Finally, because of the emergent nature of the disease, complete demographic data were absent for some patients. 


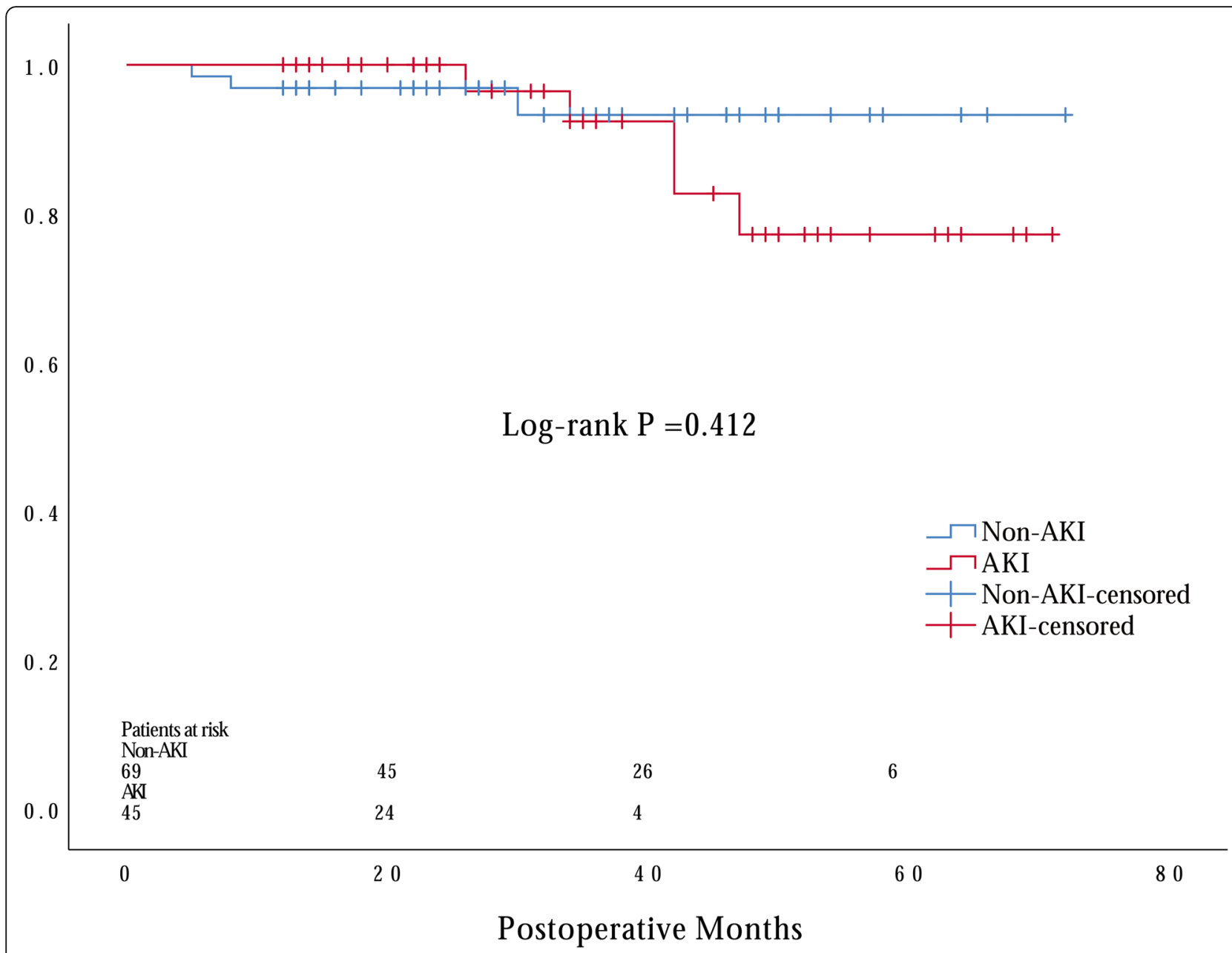

Fig. 2 Kaplan-Meier estimate for late survival of young patients operated on for type A acute aortic dissection according to the presence of postoperative acute kidney injury

\section{Conclusion}

In conclusion, AKI after TA-AAD surgery was common in young patients and associated with increased shortterm mortality. The elevated preoperative sCyC level was an independent risk factor for postoperative AKI and might be helpful in ensuring timely diagnosis.

\section{Abbreviations}

AKI: Acute kidney injury; TA-AAD: Type A acute aortic dissection; KDIGO: Kidney disease improving global outcomes; RRT: Renal replacement treatment; sCyC: Serum cystatin C; AUC: Areas under the receiver-operating characteristic curve; AD: Aortic dissection; sCr: Serum creatinine; CPB: Cardiopulmonary bypass; IQR: Interquartile; ROC: Receiver-operating characteristic; TAR: Total arch replacement; DHCA: Deep hypothermic circulatory arrest; ICU: Intensive care unit; BMI: Body mass index; LVEF: Left ventricular ejection fraction; WBC: White blood cell; PLT: Platelet; ALB: Albumin; CABG: Coronary artery bypass graft; MVR: Mitral valve replacement; MVP: Mitral valvuloplasty; TVP: Tricuspid valvuloplasty; OR: Odds ratio; Cl: Confidence interval; Pre-sCyC: Preoperative serum cystatin C; PresCr: Preoperative serum creatinine

\section{Authors' contributions}

DJW, MG, QYZ designed the study; OYZ, TC, CC collected the data; OYZ, ZGW analyzed the data; QYZ analyzed and interpreted the results; DJW support and encourage the study; QYZ wrote this article; All the authors have read and reviewed this manuscript. The author(s) read and approved the final manuscript

\section{Funding}

Not applicable.

\section{Availability of data and materials}

The datasets used or analyzed during the current study are available from the corresponding author on reasonable request.

\section{Ethics approval and consent to participate}

The study protocol was approved by the ethics committee at Nanjing Drum Tower Hospital, and all experimental methods were performed in accordance with the relevant guidelines and regulations.

\section{Consent for publication}

Consent was obtained from the patients or their relatives. 
Received: 2 August 2020 Accepted: 5 October 2020

Published online: 15 October 2020

\section{Reference}

1. Ko T, Higashitani M, Sato A, Uemura Y, Norimatsu T, Mahara K, et al. Impact of Acute Kidney Injury on Early to Long-Term Outcomes in Patients Who Underwent Surgery for Type A Acute Aortic Dissection. Am J Cardiol. 2015 116(3):463-8. Epub 2015/06/01. https://doi.org/10.1016/j.amjcard.2015.04. 043. PubMed PMID: 26026862

2. Sasabuchi Y, Kimura N, Shiotsuka J, Komuro T, Mouri H, Ohnuma T, et al. Long-Term Survival in Patients With Acute Kidney Injury After Acute Type A Aortic Dissection Repair. Ann Thorac Surg. 2016;102(6):2003-9. Epub 2016/ 07/04. https://doi.org/10.1016/j.athoracsur.2016.05.006. PubMed PMID: 27372373.

3. Elahi M, Asopa S, Pflueger A, Hakim N, Matata B. Acute kidney injury following cardiac surgery: impact of early versus late haemofiltration on morbidity and mortality. Eur J Cardiothorac Surg. 2009;35(5):854-63. Epub 2009/02/14. https://doi.org/10.1016/j.ejcts.2008.12.019. PubMed PMID: 19216088.

4. Januzzi JL, Isselbacher EM, Fattori R, Cooper JV, Smith DE, Fang J, et al. Characterizing the young patient with aortic dissection: results from the International Registry of Aortic Dissection (IRAD). J Am Coll Cardiol. 2004; 43(4):665-9. Epub 2004/02/21. https://doi.org/10.1016/j.jacc.2003.08.054. PubMed PMID: 14975480

5. Tsai SH, Lin YY, Hsu CW, Chen YL, Liao MT, Chu SJ. The characteristics of acute aortic dissection among young Chinese patients: a comparison between Marfan syndrome and non-Marfan syndrome patients. Yonsei Med J. 2009:50(2):239-44. Epub 2009/05/12. https://doi.org/10.3349/ymj.2009.50.2. 239. PubMed PMID: 19430557; PubMed Central PMCID: PMCPMC2678699.

6. Kimura N, Tanaka M, Kawahito K, Itoh S, Okamura H, Yamaguchi A, et al. Early- and long-term outcomes after surgery for acute type a aortic dissection in patients aged 45 years and younger. Circ J. 2011;75(9):2135-43. Epub 2011/06/30. https://doi.org/10.1253/circj.cj-10-1222. PubMed PMID: 21712608.

7. Kidney Disease: Improving Global Outcomes(KDIGO) Acute Kidney Injury Work Group. KDIGO Clinical Practice Guideline for Acute Kidney Injury. Kidney Inter. 2012;2(Suppl):1-138.

8. Arnaoutakis GJ, Bihorac A, Martin TD, Hess PJ, Jr., Klodell CT, Ejaz AA, et al. RIFLE criteria for acute kidney injury in aortic arch surgery. J ThoracCardiovasc Surg. 2007;134(6):1554-60; discussion 60-1. Epub 2007/ 11/21. https://doi.org/10.1016/j.jtcvs.2007.08.039. PubMed PMID: 18023682.

9. Roh GU, Lee JW, Nam SB, Lee J, Choi JR, Shim YH. Incidence and risk factors of acute kidney injury after thoracic aortic surgery for acute dissection. Ann Thorac Surg. 2012;94(3):766-71. Epub 2012/06/26. https://doi.org/10.1016/j. athoracsur.2012.04.057. PubMed PMID: 22727320.

10. Wu HB, Ma WG, Zhao HL, Zheng J, Li JR, Liu O, et al. Risk factors for continuous renal replacement therapy after surgical repair of type A aortic dissection. J Thorac Dis. 2017:9(4):1126-32. Epub 2017/05/20. https://doi. org/10.21037/jtd.2017.03.128. PubMed PMID: 28523169; PubMed Central PMCID: PMCPMC5418294.

11. Coca SG, Singanamala S, Parikh CR. Chronic kidney disease after acute kidney injury: a systematic review and meta-analysis. Kidney Int. 2012;81(5): 442-8. Epub 2011/11/25. https://doi.org/10.1038/ki.2011.379. PubMed PMID: 22113526; PubMed Central PMCID: PMCPMC3788581.

12. Wang Z, Ge M, Chen T, Chen C, Zong Q, Lu L, et al. Independent risk factors and the long-term outcomes for postoperative continuous renal replacement treatment in patients who underwent emergency surgery for type a acute aortic dissection. J Cardiothorac Surg. 2020;15(1):100. Epub 2020/05/18. https://doi.org/10.1186/s13019-020-01153-8. PubMed PMID: 32414388; PubMed Central PMCID: PMCPMC7226713.

13. Apaydin AZ, Buket $S$, Posacioglu H, Islamoglu F, Calkavur T, Yagdi $T$, et al. Perioperative risk factors for mortality in patients with acute type A aortic dissection. Ann Thorac Surg. 2002;74(6):2034-9; discussion 9. Epub 2003/03/ 20. https://doi.org/10.1016/s0003-4975(02)04096-1. PubMed PMID: 12643392

14. Jussli-Melchers J, Panholzer B, Friedrich C, Broch O, Renner J, Schottler J, et al. Long-term outcome and quality of life following emergency surgery for acute aortic dissection type A: a comparison between young and elderly adults. Eur J Cardiothorac Surg. 2017;51(3):465-71. Epub 2017/01/24. https:// doi.org/10.1093/ejcts/ezw408. PubMed PMID: 28111360.

15. Matsushita A, Tabata M, Fukui T, Sato Y, Matsuyama S, Shimokawa T, et al Outcomes of contemporary emergency open surgery for type A acute aortic dissection in elderly patients. J Thorac Cardiovasc Surg. 2014;147(1): 290-4. Epub 2012/12/12. https://doi.org/10.1016/j.jtcvs.2012.11.007. PubMed PMID: 23228401

16. Tsai HS, Tsai FC, Chen YC, Wu LS, Chen SW, Chu JJ, et al. Impact of acute kidney injury on one-year survival after surgery for aortic dissection. Ann Thorac Surg. 2012;94(5):1407-12. Epub 2012/09/04. https://doi.org/10.1016/j. athoracsur.2012.05.104. PubMed PMID: 22939248.

17. Takahashi T, Hasegawa T, Hirata N, Endo A, Yamasaki Y, Ashida K, et al. Impact of acute kidney injury on in-hospital outcomes in patients with DeBakey type III acute aortic dissection. Am J Cardiol. 2014;113(11):1904-10. Epub 2014/05/20. https://doi.org/10.1016/j.amjcard.2014.03.023. PubMed PMID: 24837272

18. Zappitelli M, Greenberg JH, Coca SG, Krawczeski CD, Li S, Thiessen-Philbrook $H R$, et al. Association of definition of acute kidney injury by cystatin C rise with biomarkers and clinical outcomes in children undergoing cardiac surgery. JAMA Pediatr. 2015;169(6):583-91. Epub 2015/04/07. https://doi.org/ 10.1001/jamapediatrics.2015.54. PubMed PMID: 25844892; PubMed Central PMCID: PMCPMC4506750.

19. Wang $X$, Lin $X$, Xie B, Huang $R$, Yan $Y$, Liu $S$, et al. Early serum cystatin Cenhanced risk prediction for acute kidney injury post cardiac surgery: a prospective, observational, cohort study. Biomarkers. 2020;25(1):20-6. Epub 2019/11/07. https://doi.org/10.1080/1354750X.2019.1688865. PubMed PMID: 31686541.

20. Parikh CR, Coca SG, Thiessen-Philbrook H, Shlipak MG, Koyner JL, Wang Z, et al. Postoperative biomarkers predict acute kidney injury and poor outcomes after adult cardiac surgery. J Am Soc Nephrol. 2011;22(9):1748-57. Epub 2011/08/13. https://doi.org/10.1681/ASN.2010121302. PubMed PMID: 21836143; PubMed Central PMCID: PMCPMC3171945.

21. Wang Z, Ge M, Chen T, Chen C, Zong Q, Lu L, et al. Acute kidney injury in patients operated on for type A acute aortic dissection: incidence, risk factors and short-term outcomes. Interactive CardioVascular and Thoracic Surgery. 2020. https://doi.org/10.1093/icvts/ivaa164.

22. Odutayo A, Cherney D. Cystatin C and acute changes in glomerular filtration rate. Clin Nephrol. 2012;78(1):64-75. Epub 2012/06/27. https://doi. org/10.5414/cn107324. PubMed PMID: 22732340.

23. Dharnidharka VR, Kwon C, Stevens G. Serum cystatin C is superior to serum creatinine as a marker of kidney function: a meta-analysis. Am J Kidney Dis. 2002;40(2):221-6. Epub 2002/07/31. https://doi.org/10.1053/ajkd.2002.34487. PubMed PMID: 12148093.

24. Liu YJ, Sun HD, Chen J, Chen MY, Ouyang B, Guan XD. Klotho: a novel and early biomarker of acute kidney injury after cardiac valve replacement surgery in adults. Int J Clin Exp Med. 2015;8(5):7351-8. Epub 2015/07/30. PubMed PMID: 26221275; PubMed Central PMCID: PMCPMC4509220.

25. Yim H, Kym D, Seo DK, Yoon J, Yang HT, Lee J, et al. Serum cystatin C and microalbuminuria in burn patients with acute kidney injury. Eur J Clin Invest. 2015;45(6):594-600. Epub 2015/04/22. https://doi.org/10.1111/eci.12452. PubMed PMID: 25892358.

26. Lassnigg A, Schmidlin D, Mouhieddine M, Bachmann LM, Druml W, Bauer P, et al. Minimal changes of serum creatinine predict prognosis in patients after cardiothoracic surgery: a prospective cohort study. J Am Soc Nephrol. 2004;15(6):1597-605. Epub 2004/05/22. https://doi.org/10.1097/01.asn. 0000130340.93930.dd. PubMed PMID: 15153571.

27. Herget-Rosenthal S, Marggraf G, Husing J, Goring F, Pietruck F, Janssen O, et al. Early detection of acute renal failure by serum cystatin C. Kidney Int. 2004;66(3):1115-22. Epub 2004/08/26. https://doi.org/10.1111/j.1523-1755. 2004.00861.x. PubMed PMID: 15327406.

\section{Publisher's Note}

Springer Nature remains neutral with regard to jurisdictional claims in published maps and institutional affiliations. 